\title{
Places: People, Events, Loci - the Relation of Semantic Frames in the Construction of Place
}

\author{
Steve Harrison ${ }^{1} \&$ Deborah Tatar $^{2}$ \\ ${ }^{1}$ Department of Computer Science and Art and Art History, Virginia Tech, 121 VTKW II - 0106, \\ 2202 Kraft Dr., Blacksburg, VA 24060, USA (E-mail: sHarrison@vt.edu); ${ }^{2}$ Dept of Computer \\ Science and Psychology, Virginia Tech, 123 VTKW II - 0106, 2202 Kraft Dr., Blacksburg, VA \\ 24060,USA (E-mail: tatar@vt.edu)
}

\section{Erratum to: Computer Supported Cooperative Work (CSCW) DOI 10.1007/s10606-007-9073-0}

Unfortunately, the following error was not discovered until after the paper had been finalized and corrections were no longer possible.

In the paper by Harrison, S. and Tatar, D., "Places: People, Events, Loci" - the Relation of Semantic Frames in the Construction of Place," on page 126, on lines 5-6 the authors state:

Quoting from Brewer and Dourish (elsewhere in this Journal)

However, the paper by Brewer and Dourish is not published in this journal issue.

The Editors

$\overline{\text { The online version of the original article can be found at doi:10.1 }} 007 /$ s10606-007-9073-0. 